\title{
The influence of the spraying angle on properties of thermally sprayed HVOF cermet coatings
}

\author{
Š. Houdková, F. Zahálka \& M. Kašparová \\ ŠKODA VÝZKUM s.r.o., Czech Republic
}

\begin{abstract}
The tribological properties of the surfaces of parts, namely their wear resistance and friction properties, are in many cases decisive for their proper function. To improve surface properties, it is possible to create hard, wear resistant coatings by thermal spray technologies. Using these versatile coatings it is possible to increase the lifetime, reliability and safety of parts. For proper function of the surface treatment it is necessary to find and keep the optimal condition and parameters during preparation, deposition and further processing of the sprayed part. The spraying angle is one of the deposition parameters that influence the quality of thermally sprayed coatings. According to the theory, with decreasing spraying angle the process deposition efficiency decreases, whereas the porosity of coatings increases, being a cause of aggravated microstructure and mechanical properties. In this paper, the microstructure together with the basic mechanical properties and wear of $\mathrm{WC}-\mathrm{Co}$ and $\mathrm{Cr}_{3} \mathrm{C}_{2}-\mathrm{NiCr} \mathrm{HVOF}$ sprayed coatings were investigated in dependence of the spraying angle. For each coating, the marginal spraying angle that can be used without a significant decrease of the coating's quality was identified. With respect to the change in coating properties as well as to process deposition efficiency, the maximum $30^{\circ}$ diversion from a normal spray direction is recommended in the case of $\mathrm{WC}-\mathrm{Co}$ and $15^{\circ}$ diversion in the case of $\mathrm{Cr}_{3} \mathrm{C}_{2}-\mathrm{NiCr}$.
\end{abstract}

Keywords: thermal spraying, coating, HVOF, spraying angle, cermet, WC-Co, $\mathrm{Cr}_{3} \mathrm{C}_{2}-\mathrm{NiCr}$. 


\section{Introduction}

The tribological properties of the surfaces of parts, namely their wear resistance and friction properties, are in many cases decisive for their proper function. To improve surface properties, it is possible to create hard, wear resistant coatings by thermal spray technologies. Using these versatile coatings it is possible to increase the lifetime, reliability and safety of parts. Thermal spraying is an expanding area within the technology of surface engineering. It is a process that involves the deposition of molten or semi-molten droplets of powder onto a substrate to form a coating. A wide range of materials can be thermally sprayed for a variety of applications ranging from gas turbine technology to the electronics industry. For the creation of hard, wear and corrosion resistant coatings the most suitable materials are ceramics and hard metals. For spraying ceramics, which need to be melted under very high temperatures, plasma spraying is the technology used. For hard metals, the best way is to use the HVOF technology that was developed for spraying hard metals to get the highquality coatings. In high velocity oxy-fuel (HVOF) thermal spraying, oxygen and fuel gas flow at high pressures and flow rates with internal combustion produces very high particle velocities with relatively low temperatures compared with other thermal spray processes, such as air or vacuum plasma spraying [1]. As a result, HVOF has a capability for producing dense coatings with low degrees of decomposition, which are well bonded to the substrate. As a line-of sight process, HVOF has application limitations with respect to part geometry, particularly in coating small internal diameters. It is often not possible to realize a perpendicular spraying angle. This can lead to significant changes of coating properties. In the literature the influence of the spray angle was studied in terms of microstructure, hardness, surface roughness and deposition efficiency [2-5]. It is generally considered, that spraying at angles of up to $45^{\circ}$ guaranties a successful application with only a marginal loss of coating quality. To verify these statements for particular coating materials, the investigation of spray angle influence on deposition processes and coating properties was provided for HVOF TAFA JP-5000 sprayed WC-17\%Co and $\mathrm{Cr}_{3} \mathrm{C}_{2}-25 \% \mathrm{NiCr}$ coatings. This study can provide fundamentals to determine the tolerance to which coatings exhibit reproducible properties.

\section{Experimental}

The coatings were sprayed using TAFA JP-5000 spraying equipment onto gritblasted carbon steel EN 10025-90 using spray parameters that were previously optimized at a spray angle of $90^{\circ}$ [6]. The basic spraying parameters are summarized in Table 1.

Table 1: $\quad$ Spraying parameters.

\begin{tabular}{llllll}
\hline Coating & Powder & Eq. ratio & Carrier gas & $\begin{array}{l}\text { Barrel } \\
\text { length }\end{array}$ & $\begin{array}{l}\text { Spraying } \\
\text { distance }\end{array}$ \\
\hline $\mathrm{WC}-\mathrm{Co}$ & FST K-674.23 & 0.8 & Argon, $414 \mathrm{kPa}, 8 \mathrm{sl} / \mathrm{h}$ & $150 \mathrm{~mm}$ & $380 \mathrm{~mm}$ \\
$\mathrm{Cr}_{3} \mathrm{C}_{2}-\mathrm{NiCr}$ & $1375 \mathrm{VM}$ & 0.8 & Argon, 345 kPa, $8 \mathrm{sl} / \mathrm{h}$ & $150 \mathrm{~mm}$ & $360 \mathrm{~mm}$ \\
\hline
\end{tabular}


Five different spray angles were used to spray the samples: $90^{\circ}, 60^{\circ}, 75^{\circ}$, $45^{\circ}$ and $30^{\circ}$. For each spraying angle, a different number of passes was applied to reach similar coating thicknesses of all samples.

\subsection{Microstructure}

The WC-15\%Co powder for HVOF spraying consists of hard particles of WC, surrounded by a tough Co matrix. Due to oxidation during the deposition process, part of the $\mathrm{WC}$ decomposes to $\mathrm{W}_{2} \mathrm{C}$ and $\mathrm{W}$, producing $\mathrm{CO}$ and $\mathrm{CO}_{2}$. Together with the oxidation process, dissolution of $\mathrm{W}$ and $\mathrm{C}$ in the Co matrix takes place. As a result of rapid solidification of droplets after the impact, the matrix includes amorphous or fine-grained structures, which could later give rise to precipitation of $\mathrm{W}$ or so called $\eta$ phases (in particular $\mathrm{Co}_{3} \mathrm{~W}_{3} \mathrm{C}$ and $\mathrm{Co}_{6} \mathrm{~W}_{6} \mathrm{C}$ ). Decarburization and formation of brittle $\eta$ phases is an undesirable effect leading to a loss of the tough Co matrix. The presence of the above mentioned phases in HVOF sprayed WC-Co coatings were described in literature many times [7, 8].

The $\mathrm{Cr}_{3} \mathrm{C}_{2}-25 \% \mathrm{NiCr}$ coating's microstructure includes beyond hard $\mathrm{Cr}_{3} \mathrm{C}_{2}$ carbides, $\mathrm{NiCr}$ matrix, $\mathrm{Cr}_{2} \mathrm{O}_{3}$, originated from the oxidation process during spraying, and also lower carbides $\mathrm{Cr}_{7} \mathrm{C}_{3}$ and $\mathrm{Cr}_{26} \mathrm{C}_{6}$ with a hardness lower than the initial $\mathrm{Cr}_{3} \mathrm{C}_{2}$, originated from the decarburization process similarly to $\mathrm{WC}$ Co. Due to the dissolution of carbides in the matrix, the concentration of $\mathrm{C}$ and $\mathrm{Cr}$ in the matrix of the coating is higher compared to the powder material. It enables the melted droplets to solidify as a quasi-amorphous or nano-crystallic structure. Other nano-crystallic phases, with a grain size around $10 \mathrm{~nm}$, formed of $\mathrm{Ni}$ and $\mathrm{Co}$, appear in the coatings microstructure as a result of rapid solidification $[8,9]$.

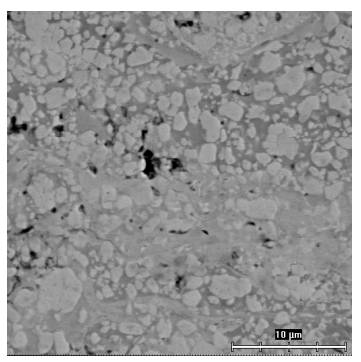

$90^{\circ}$

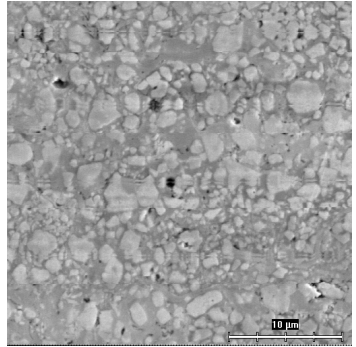

$75^{\circ}$

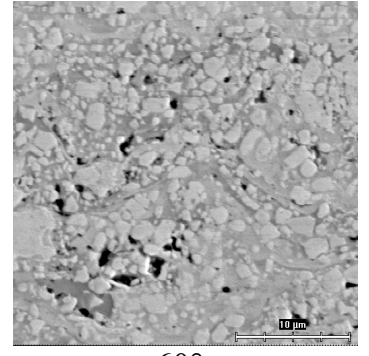

$60^{\circ}$

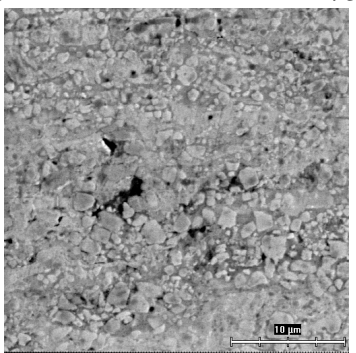

$45^{\circ}$

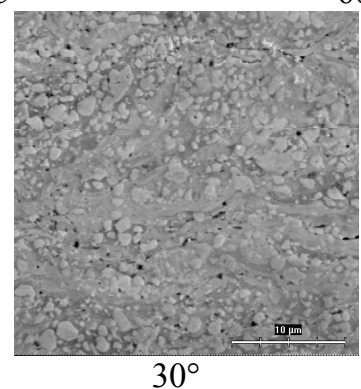

Figure 1: $\quad$ Microstructure of WC-Co coatings. 
The influence of the spray angle on the coatings microstructure was studied by optical microscopy and SEM, in two directions (longitudinal and transversal) to the direction of spraying.

The microstructure of all studied WC-Co coatings is homogenous, without cracks or unmelted particles. Just a minor amount of porosity is included in the coating; the carbide distribution in the matrix is uniform. No obvious influence of spray angle was observed. In the case of $\mathrm{Cr}_{3} \mathrm{C}_{2}-\mathrm{NiCr}$ coating, the microstructure is without visible changes up to the spray angle $75^{\circ}$. Coatings sprayed at $60^{\circ}$ and lower showed longitudinal and lateral cracks, also on the substrate-coating boundary. Only negligible changes in porosity were observed for both coatings, in contradiction to expected effect of shielding [10] and results of Tillmann et al. [3] study, focused on APS WC-Co and $\mathrm{Cr}_{3} \mathrm{C}_{2}$-Nicr coatings. Moreover, the amount of porosity in the coatings sprayed under $30^{\circ}$ is lower than in the coatings sprayed under $60^{\circ}$ and $45^{\circ}$.

\subsection{Hardness and microhardness}

The hardness HR15N was measured on the surfaces of the coatings according to EN ISO 6508-1, microhardness HV0,3 was measured on coatings cross sections in both directions - longitudinal and transversal - to direction of spraying according to EN ISO 6507-1.

As expected, the hardness and microhardness of WC-Co coating was higher compared to $\mathrm{Cr}_{3} \mathrm{C}_{2}-\mathrm{NiCr}$ coating. The surface hardness of both coatings showed decrease in values for $75^{\circ}$ spray angle, followed by unexpected increase for $60^{\circ}$ spray angle. After that, the HR15N values decreased together with the spray angle. No measurement of surface hardness in dependence on spray angle was found in available literature.

The microhardness results showed continuous decrease with decreasing spray angle, which is in correlation with results of Strock et al. [2]. Tillmann et al. [3] did not find any dependence between microhardness and spray angle. The hardness and microhardness results are shown in Figure 2 and 3.

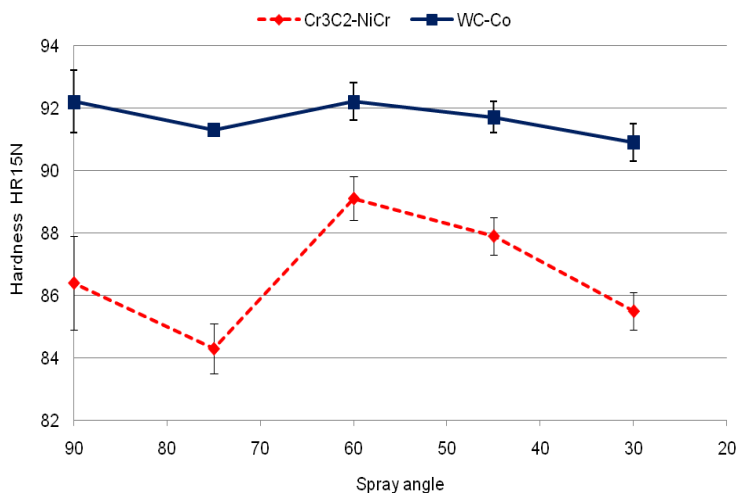

Figure 2: $\quad$ Surface hardness of the coatings. 


\subsection{Residual stress}

Residual stress correlations were made using so-called Almen strip test method. The method is based on the measurement of deflection of coated thin metal strip. The measurement is only qualitative, the value of stress cannot be directly determined $[11,12]$.

Generally, HVOF coatings tend thanks to high impact velocities of droplets to have compressive residual stress, which is beneficial for their properties. In our case, compressive residual stress appeared only at WC-Co coating, while tensile residual stress occurred at $\mathrm{Cr}_{3} \mathrm{C}_{2}-\mathrm{NiCr}$ coating. The tensile stress component increased with spray angle decreasing from $90^{\circ}$ for both coatings, although at $30^{\circ}$ spray angle the level of tensile stress slightly decreased. The increasing in the tensile stress level with decreasing spray angle is observed also by Strock et al. [2]. The level of the coatings residual stress is shown in Figure 4.

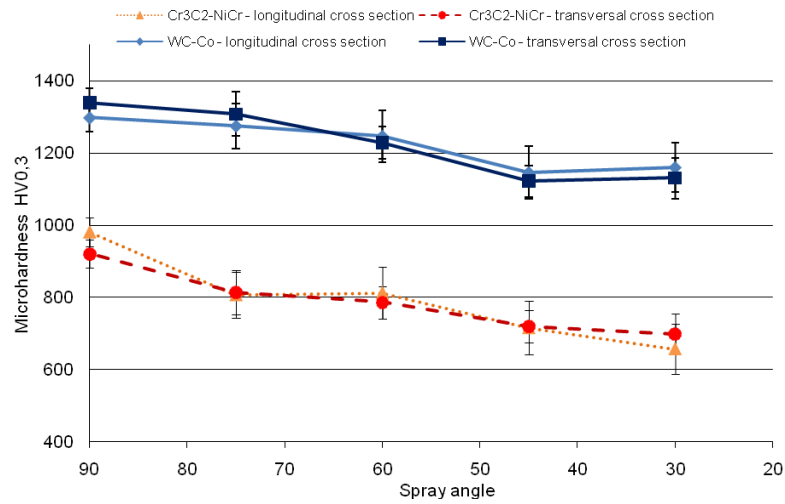

Figure 3: Microhardness of the coatings.

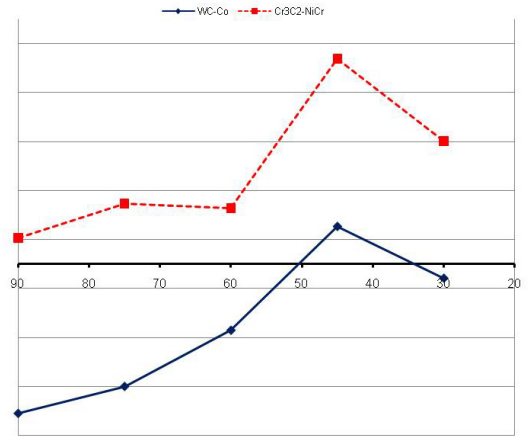

Figure 4: The level of residual stress. 


\subsection{Indentation fracture toughness}

The resistance of coatings against the fracture spreading of brittle materials can be measured by Vickers indentation method. The technique of indentation fracture toughness measurement, described in detail by Ponton and Rawlings [13], can be successfully used for evaluation of thick brittle coatings [14-16]. In this case, the model of Lawn and Swain [17] was used to determine the number of $\mathrm{K}_{\mathrm{Ic}}$. The results of measurement are displayed in Figure 5.

The resistance of WC-Co coating against the fracture spreading expressed by KIc decreased together with spray angle decreasing from $90^{\circ}$, with a slight increase at $60^{\circ}$. The tendency is similar to the tendency of superficial hardness HR15N (see Fig. 2). The $\mathrm{Cr}_{3} \mathrm{C}_{2}-\mathrm{NiCr}$ behaved as more brittle compared to WCCo. The cracks were much longer and scatter of the results was much higher. No significant dependence of KIc on spray angle was observed. Either the spray angle does not influence the $\mathrm{Cr}_{3} \mathrm{C}_{2}-\mathrm{NiCr}$ cracking behavior, or, more probably, the dependence is under the resolution limits of the used method.

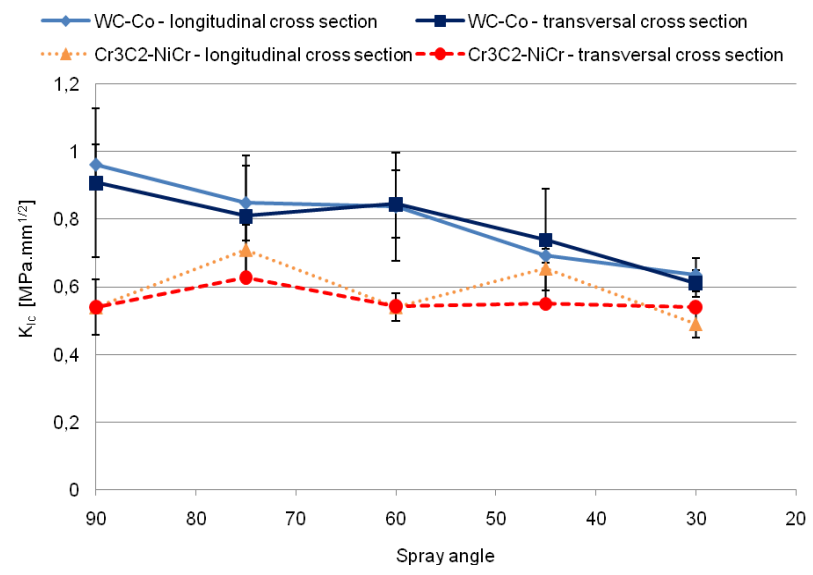

Figure 5: Indentation fracture toughness of the coatings.

\subsection{Surface roughness}

The surface roughness measurement was done in both directions, longitudinal and transverse, to the direction of spraying. For both coatings, the surface roughness expressed by $\mathrm{Ra}$ decreased with spray angle decreasing from $90^{\circ}$, with the exception of $30^{\circ}$ sprayed WC-Co coatings, where the slight increase could be noticed. In both cases, the surface roughness in longitudinal direction is gently higher compared to $\mathrm{Ra}$ in the transversal direction. For APS sprayed coatings, Tillmann et al. [3] present opposite tendency.

The technological conclusion is that there is no need to increase the machining allowance in the case of off-angle sprayed coatings. 


\subsection{Specific density}

Specific density of the coatings was measured by the method, based on the Archimedes law. The differences in values for each coating material represent the different amount of porosity in the coatings. The results are shown in Figure 7. The density measurement, with respect to the measurement error, does not exhibit any clear dependence on the spray angle. A sudden increase of density for coatings sprayed at $30^{\circ}$, correlating with the result of microstructure evaluation, is interesting.

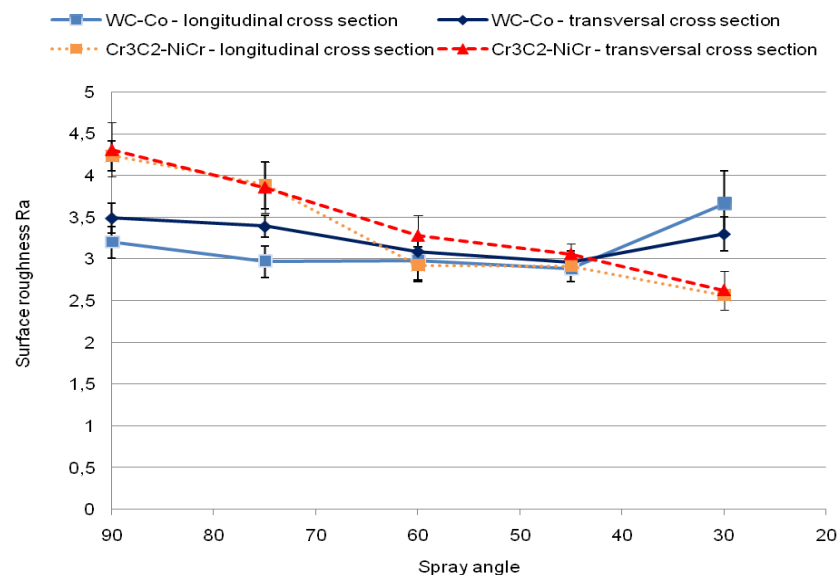

Figure 6: Surface roughness Ra values.

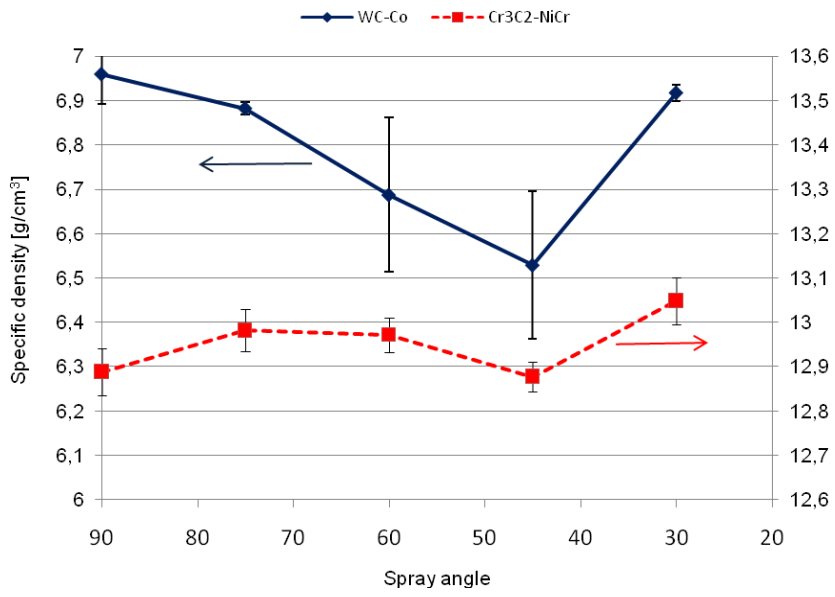

Figure 7: Density of the coatings. 


\subsection{Deposition efficiency}

The deposition efficiency of spraying process was determined according to EN ISO 17836. From the measured results (Figure 8) it is clearly visible, that the deposition efficiency is strongly dependent on the spray angle. The deposition efficiency is one of the main parameters that affect the economy of the thermal spray process. From this point of view it is noticeable that the process of spraying is not very effective even for $90^{\circ}$ spray angle (only $40 \%$ deposition efficiency).

\subsection{Wear}

Wear resistance of coating was tested by Dry Sand/Rubber Wheel test according to ASTM G-65. The principle of the method enables to evaluate the tree-body abrasive wear under the low-stress condition. The wear is characterized by the wear rate, calculated from the coating volume loss and the abrasive distance.

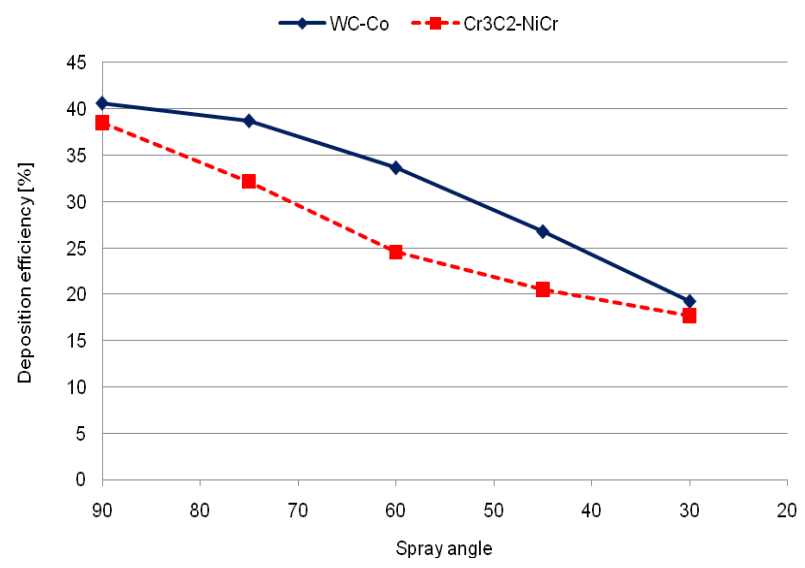

Figure 8: Deposition efficiency.

The WC-Co coating is approximately 5 times more wear resistant compared to $\mathrm{Cr}_{3} \mathrm{C}_{2}-\mathrm{NiCr}$ coating (Figure 9). Both coatings met the expectation of decreasing the wear resistance with decreasing spray angle. For WC-Co coating, the difference between the wear rate of coatings sprayed at $90^{\circ}, 75^{\circ}$ and $60^{\circ}$ was very small and their wear resistance can be considered equal. The coatings, sprayed at the lower spray angles, especially $30^{\circ}$, had significantly worse wear behavior. For $\mathrm{Cr}_{3} \mathrm{C}_{2}-\mathrm{NiCr}$ coating, the equal wear behavior can be observed for coatings sprayed under $90^{\circ}$ a $75^{\circ}$ spray angle. Theoretical models [17] predict the wear rate to be dependent on materials hardness: $1 / \mathrm{H}$ for tough materials and $1 / \mathrm{H}^{2}$ for brittle materials. Such a clear dependence was not confirmed in our measurements. The results of the Dry Sand Rubber Wheel test are in contradiction with results of Strock et al. [2], who found an opposite dependence 
in the fretting wear test. In spite of lower hardness and lower compressive residual stress, the off-angle $\mathrm{WC}-\mathrm{CoCr}$ coatings exhibited less wear than $90^{\circ}$ coatings. He explained this unexpected behavior by more uniform distribution of phases across the surface at off-angle coatings that was not observed in our case. The contradiction can also be caused by differences between wear conditions of the fretting and the abrasive wear test.

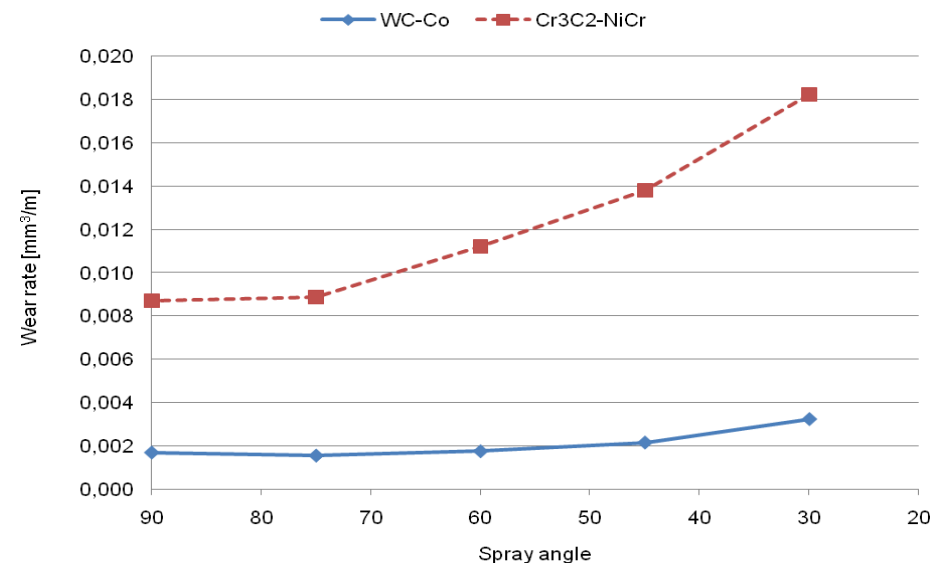

Figure 9: Wear rate.

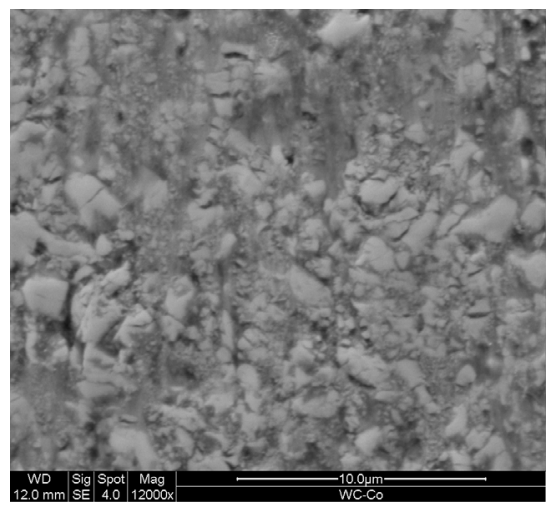

$90^{\circ}$

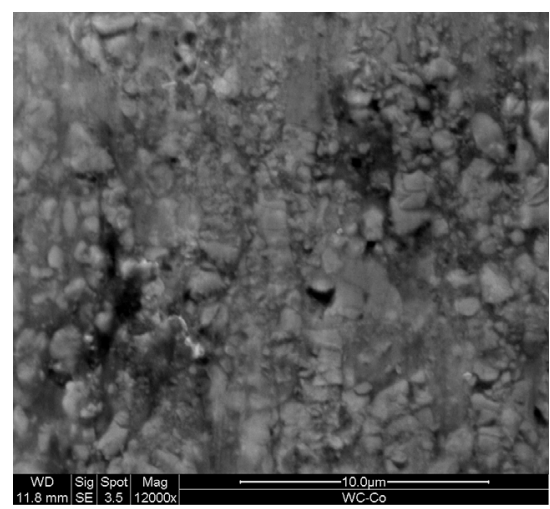

$30^{\circ}$

Figure 10: Wear track of WC-Co coatings after the Dry Sand/Rubber Wheel test.

The mechanism of wear was studied using SEM. The micrographs of the worn surface match the wear rate results. The wear mechanism of perpendicularly sprayed coating can be characterized by the gradual loss of metal matrix followed by decrease in carbide-matrix cohesion and pull-off the carbides. The coatings, sprayed at lower angles, exhibit massive wear 
represented not only by pull-off the carbides, but also by pull-off parts of whole splats. Such a behavior indicates low intersplat cohesion in the coating.

\section{Summary and conclusion}

The evaluation of the spray angle influence on physical, mechanical and technological parameters of the HVOF hard metal coatings showed a significant dependence of the coating properties on the spray angle. During the results' analyses some interesting correlations occurred. The trend of the surface hardness measurements and the indentation fracture toughness of WC-Co coating are almost similar. The results of microhardness and residual stress measurement are conformable to each other, but not to surface hardness and indentation fracture toughness, although it could be expected. The explanation could be in the load range, used for the measurement. Microhardness with the load of $300 \mathrm{~g}$ is measured within one splat, while surface hardness with the load of $15 \mathrm{~kg}$ includes information from several splats as well as the indentation fracture toughness $(200 \mathrm{~kg})$. Surface hardness indentation fracture measurements take place on the same microstructure "scale" and are influenced by the same coating's microstructure features: pores, oxides, splat boundaries etc., while the microhardness measurement is closer to the measurement of a bulk material.

The properties of WC-Co coatings sprayed at $30^{\circ}$ are surprising in general. Contrary to expectation its microstructure, density, microhardness, residual stress and surface roughness are better compared to the coating sprayed at $45^{\circ}$. For $\mathrm{Cr}_{3} \mathrm{C}_{2}$-NiCr coating the same effect was observed only for the density and the residual stress.

However, whatever thee mechanical and physical properties of coatings sprayed at $30^{\circ}$ are, no increase in their wear resistance was observed. It is caused probably by a low intersplat cohesion, or a low adhesion of coating to the substrate connected with imperfect spreading and emplacement of droplets to the originating coatings microstructure during spraying at low angles. This hypothesis would be necessary to confirm by test of adhesive/cohesive strength.

Based on the measured data, using the spray angle up to $60^{\circ}$ for $\mathrm{WC}-\mathrm{Co}$ $\mathrm{HVOF}$ coating, and up to $75^{\circ}$ for $\mathrm{Cr}_{3} \mathrm{C}_{2}-\mathrm{NiCr} \mathrm{HVOF}$ coating can be recommended. These coatings are fully acceptable both from the functional and the economical point of view.

\section{Acknowledgement}

This paper was written thanks to the project of the Czech Ministry of Education, Youth and Sports no. MSM 4771868401

\section{References}

[1] Smith, E. B., Power, T. J., Barber, T. J., United Technology Research Centre Report, East Hartford, CT, (1991), p.91

[2] Strock, E., Ruggiero, P., Reynolds, D., The effect of off-angle spraying on the structure and properties of $\mathrm{HVOF} \mathrm{WC} / \mathrm{CoCr}$ coatings, Proc. of 
International Thermal Spray Conference 2001, May 28-30 2001, Singapore, 671- 676, 2001

[3] Tillmann, W. Vogli, E., Krebs, B., Influence of the spraying angle on characteristics for atmospheric plasma sprayed hard material base coatings, Proc. Of International Thermal Spray Conference 2008, June 2-4 2008, Maastricht, 235-240, 2008

[4] Smith, M. F., Neiser, R. A., Dykhuizen, R. C., An investigation of the effects of droplet impact angle in thermal spray deposition, Proc. Of 7th National Thermal Spray Conference 1994, June 20-24, 1994, Boston, 603608, 1994

[5] Leigh, S. H., Berndt, C. C., Evaluation of off-angle thermal spray, Surface and Coatings technology, 89, 213-224, 1997

[6] Houdková, Š., Enžl, R., Fiala, P., Bláhová, O., Mechanical properties of HVOF coatings, Proceedings of University of West Bohemia 2001, 5, 7383,2002

[7] Schwetzke, R., Kreye, H., Microstructure and properties of tungsten carbide coatings sprayed with various high velocity oxygen fuel spray system, Journal of Thermal Spray Technol. 8, 433-439, 1999

[8] Berger, L.-M., Chemistry of carbide-metal composites for preparation of HVOF sprayed coatings, Papers, Materials Week 2001, Int. Conf. on Adv. Mater., their Processes and Applications, 1- 4 October 2001, München, 10, 2001

[9] Zimmermann, S., Kreye, H., Chromium carbide Coatings produced with Various HVOF Spray Systems, Proc. of the 9th National Thermal Spray Conf., Cincinnati, 147-152, 1996

[10] Davis J. R., Davis \& Associates, Handbook of Thermal Spray Technology, ASM International, 2004

[11] SAE J442 Revised Dec. 2001: Test Strip, Holder, and gage for Shot Peening

[12] SAE J443 Revised Jan. 2003: Procedures for Using Standard Shot Peening Test Strip

[13] Ponton, C. B., Rawlings, R. D., Materials Science and Technology, 5, 865872,1989

[14] Li, H., Khor, K. A., Cheang, P., Young's modulus and fracture toughness determination of high velocity oxy-fuel-sprayed bioceramic coatings, Surface and Coatings Technology, 155, 21-32, 2002

[15] Brantnrer, H. P., Pippan, R., Prantl, W., Local and global fracture toughness of flame sprayed molybdenum coatings, Journal of Thermal Spray Technology, 12, 560-571, 2003

[16] Giolli, C., Scrivani, A., Rizzi, G., Borgioli, F., Bolelli, G., Lusvarghi, L., Failure mechanism for thermal barrier coating systems, Proc. Of International Thermal Spray Conference 2008, June 2-4 2008, Maastricht, 460-467, 2008

[17] Lawn, B. R., Swain, M. V., Journal of Mater. Science, 10, 113-122, 1975

[18] Hutchings, I. M., Abrasive and erosive Wear: Wear by Hard Particles, in Wear Fundamentals for Engineering, Elsevier, 1999, 